\title{
Novel Design Strategy for Checkpoint Kinase 2 Inhibitors Using Pharmacophore Modeling, Combinatorial Fusion, and Virtual Screening
}

\author{
Chun-Yuan Lin ${ }^{1,2}$ and Yen-Ling Wang \\ ${ }^{1}$ Department of Computer Science and Information Engineering, Chang Gung University, Taoyuan 33302, Taiwan \\ ${ }^{2}$ Research Center for Emerging Viral Infections, Chang Gung University, Taoyuan 33302, Taiwan \\ Correspondence should be addressed to Chun-Yuan Lin; cyulin@mail.cgu.edu.tw
}

Received 29 November 2013; Accepted 19 February 2014; Published 23 April 2014

Academic Editor: Che-Lun Hung

Copyright (C) 2014 C.-Y. Lin and Y.-L. Wang. This is an open access article distributed under the Creative Commons Attribution License, which permits unrestricted use, distribution, and reproduction in any medium, provided the original work is properly cited.

Checkpoint kinase 2 (Chk2) has a great effect on DNA-damage and plays an important role in response to DNA double-strand breaks and related lesions. In this study, we will concentrate on Chk2 and the purpose is to find the potential inhibitors by the pharmacophore hypotheses (PhModels), combinatorial fusion, and virtual screening techniques. Applying combinatorial fusion into PhModels and virtual screening techniques is a novel design strategy for drug design. We used combinatorial fusion to analyze the prediction results and then obtained the best correlation coefficient of the testing set $\left(r_{\text {test }}\right)$ with the value 0.816 by combining the Best $t_{\text {train }}$ Best $_{\text {test }}$ and Fast ${ }_{\text {train }}$ Fast $_{\text {test }}$ prediction results. The potential inhibitors were selected from NCI database by screening according to Best train Best $_{\text {test }}+$ Fast $_{\text {train }}$ Fast $_{\text {test }}$ prediction results and molecular docking with CDOCKER docking program. Finally, the selected compounds have high interaction energy between a ligand and a receptor. Through these approaches, 23 potential inhibitors for Chk2 are retrieved for further study.

\section{Introduction}

DNA-damage is induced by ionizing radiation, genotoxic chemicals, or collapsed replication forks, and when DNA was damaged or the responses of cells were failure, the mutation associated with the breast or ovarian cancer of genes may occur. To prevent and repair the DNA-damage, mammalian cells will control and stabilize the genome by cell cycle checkpoint. The checkpoint pathway consists of several kinases, such as ataxia telangiectasia mutated protein (ATM $[1,2]$ ), ataxia telangiectasia and Rad3-related protein (ATR $[1,2])$, checkpoint kinase $1(\mathrm{Chk} 1[3,4])$, and checkpoint kinase 2 (Chk2 [5-8]). ATM and ATR are upstream kinases passing messages to downstream kinases and phosphorylating several proteins that initiate the activation of the DNAdamage checkpoint. Moreover, ATM is a primarily pathway to activate p53 (protein 53 [9]) by Chk2, and ATR may influence the phosphorylation of Chk1. Both Chk1 and Chk2 are key components in DNA-damage; however, their cellular activities are different. Chk1 is involved in S and G2 phases of the cell cycle with ATR pathway. By contrast, Chk2 is activated in all phases through ATM-dependent pathway and plays an important role in response to DNA double-strand breaks and related lesions. Furthermore, Chk1 is an unstable protein and lacks the forkhead-associated domain (FHA) which was involved in several processes that protect against cancer and can be found in Chk2. Therefore, we concentrate on Chk2 in this study.

Chk2 is a protein containing 543 amino acid residues and the structure of Chk2 consists of some functional elements, including the $\mathrm{N}$-terminal SQ/TQ cluster domain (SCD), FHA, and the $\mathrm{N}$-terminal serine/threonine kinase domain (KD) [5-8]. The SCD is known to be the preferred site with the residue Thr68 for phosphorylation to respond to DNA-damage by ATM/ATP kinases. The FHA domain is a phosphopeptide recognition domain found in many regulatory proteins and thought to bind to the phosphoThr68 segment of SCD $[5-8,10-14]$. Hence it is a good candidate 


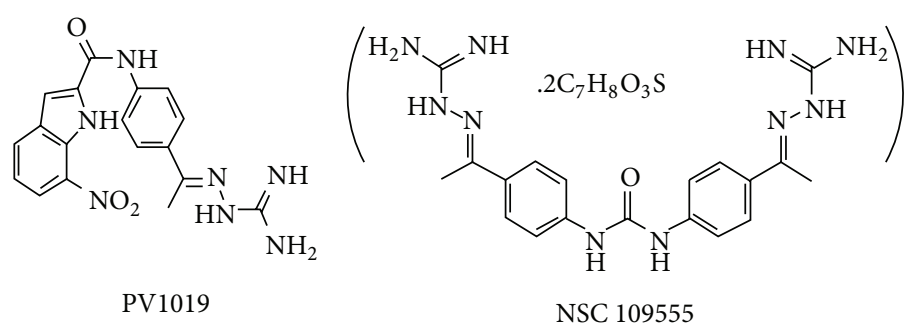

FIgure 1: Two-dimensional chemical structures of known Chk2 inhibitors. The experimental $\mathrm{IC}_{50}$ of PV1019 and NSC 109555 were $138 \mathrm{nM}$ and $240 \mathrm{nM}$, respectively.

for interactions of $\mathrm{Chk} 2$ with its upstream regulators or downstream targets in the cell-cycle-checkpoint signaling. The KD occupies almost the entire carboxy-terminal half of Chk 2 and has been identified based on their homology with serine/threonine kinases. Some studies reported that when DNA was damaged, Chk2 is activated by ATM/ATR through the phosphorylation of residue Thr68. Moreover, Chk2 induces transautophosphorylation of residues Thr383 and Thr387 and then cis-phosphorylation of residue Ser516 [5-8, 10-14]. After that, Chk2 will phosphorylate several downstream substrates, such as BRCA1 (breast cancer 1, early onset $[15,16])$, Cdc25A (cell division cycle 25 homolog A), Cdc25C, and p53 [7, 8, 10]. Several researches indicated that Chk2 phosphorylates Cdc25A which is considered an oncogene on the residue Ser123 in S phase of cell cycle, and it also phosphorylates Cdc25C on the residue Ser216 in G2 phase helping prevent mitotic entry in cells with damaged DNA [5]. Furthermore, BRCA1 and p53 are involved in DNA repair process in the breast or ovarian cancer. BRCA1 is a human caretaker gene and helps repair damaged DNA or destroys cells which cannot be repaired. The p53 is a tumor suppressor protein involved in preventing cancer in human and plays an important role in the G1 checkpoint in response to DNA damaging agents. We consider that the sites of the phosphorylations are important in the drug design for cell survival when DNA is damaged.

Recently, several studies identified the inhibitors of Chk2 [6-8, 10-14], and they also showed the crystal structures of Chk2 complex, such as PDB: 1GXC, 2W7X, and, and so forth. They are selective, reversible, and ATP-competitive Chk2 inhibitors demonstrating that they effectively restrain the radiation-induced phosphorylation of Chk2. In addition, several selective Chk2 inhibitors have been also identified (two examples were shown in Figure 1) and the researches indicated that they are potential and selective inhibitors of Chk2 with chemotherapeutic and radiosensitization potential. On structure-based drug design, several developments of Chk2 were published $[17,18]$. Quantitative structureactivity relationship model (QSAR model) is a regression or classification model and is an important technique in the rational drug design. It is used to correlate the structure properties of compounds with their biological activities. The method to predict the quality by QSAR was improved by considering the three-dimensional structure QSAR (3DQSAR) [19-24] of targeted inhibitor. Therefore, the compound structure can be directly optimized in the 3D space.
The comparative molecular field analyses (CoMFA) [18, 2530 ] and the comparative molecular similarity indices analyses (CoMSIA) [18, 27-32] for Chk2 inhibitors were performed by ligand-based and receptor-guided alignment. They used the cocrystal structure from protein data bank (PDB code: $2 \mathrm{CN} 8$ ) [7], and then they identified new plausible binding modes used as template for 3D-QSAR [18]. There is another research of Chk2 studied in QSAR/QSPR [17] providing structures that will improve reducing the side effects of Chk2 inhibitors.

Pharmacophore [20-24, 33-35] is a set of structural features responsible for the biological activity of a molecule. It allowed compounds with diverse structures to find the common chemical features by ligand pharmacophore mapping, and that is different from CoMFA and CoMSIA with the common structure constraint. Thus, pharmacophore can explain how diverse ligands bind to a receptor site by these features and visualize the feature of potential chemical interactions between ligands and receptors. Moreover, pharmacophore can easily and quickly identify candidate inhibitors for a target protein based on 3D query. Therefore, in this work, we first used 3D-QSAR study to build pharmacophore hypotheses (denoted as PhModels) for Chk2 inhibitors by HypoGen Best, Fast, and Caesar algorithms, respectively. Then we used the combinatorial fusion to select and combine prediction results for improving the predictive accuracy in biological activities of inhibitors. Virtual screening is a computational technique used in drug discovery research. There are two categories of screening techniques: ligandbased and structure-based. In this work, for ligand-based virtual screening, we used the selected PhModels as 3D structure query by pharmacophore hypothesis screening that each compound in National Cancer Institute (NCI) database will be mapped onto the pharmacophoric features of selected PhModels. When the chemical features of a compound fit the generated PhModels, it will be selected. All of feasible compounds in NCI database were selected in this work. Finally, the potential inhibitors were retrieved from selected compounds by using molecular docking program to predict the conformation and interaction energy between Chk 2 and ligand. Applying combinatorial fusion into PhModels and virtual screening techniques is a novel design strategy for drug design and can help medicinal chemists to identify or design new Chk2 inhibitors. Besides, the potential inhibitors of Chk 2 retrieved in this work can be estimated by biologists for further study. 


\section{Materials and Methods}

2.1. Biological Data Collection. In order to construct the PhModels, at first, we collected the Chk2 inhibitors with two-dimensional structures and the biological activity values from the ChEMBL database [36]. Then, according to the structure variations and chemical differences in the kinase inhibitor activity, 158 known Chk2 inhibitors were selected and retrieved. The biological activity of 158 known Chk2 inhibitors was represented as $\mathrm{IC}_{50}$ (nanomolar, $\mathrm{nM}$ ). There are 260,071 compounds from the NCI database (release version 3, http://cactus.nci.nih.gov/download/nci/) which were used in the database screening and molecular docking approach in this work.

2.2. Training and Testing Sets Selection. Before generating PhModels, we should divide the 158 Chk2 inhibitors into the training set and testing set, respectively. The rules used to select training set inhibitors are according to the following requirements as suggested by the Accelrys Discovery Studio. (1) All selected inhibitors should have clear and concise information including structure features and activity range. (2) At a minimum, 16 diverse inhibitors for training set were selected to ensure the statistical significance. (3) The training set should contain the most and the least active inhibitors.

(4) The biological activities of the inhibitors spanned at least 4 orders of magnitude. Based on the above four rules, the 158 Chk 2 inhibitors were divided, and the scatter diagram of training set and testing set inhibitors was shown in Figure 2. Figure 2 demonstrates the distribution of the inhibitors in the training set and testing set, and the representative points of the testing set are close to those of the training set. The training set with 25 inhibitors is used to construct PhModels, and the $\mathrm{IC}_{50}$ values of these 25 inhibitors are ranged from 2.3 to $100,000 \mathrm{nM}$ (Table 1). The testing set with remaining 133 inhibitors is used to test the predictive ability of generated PhModels, and the $\mathrm{IC}_{50}$ values of the 133 testing set inhibitors are ranged from 3.4 to $74,000 \mathrm{nM}$ (Table 2). After selecting the training set and testing set inhibitors, we established PhModels at first, and then we used the correlation analysis to estimate the prediction abilities of PhModels.

2.3. Pharmacophore Generation. The workflow of PhModel generation for Chk2 inhibitors was shown in Figure 3. In this study, we used the HypoGen program [37] in Accelrys Discovery Studio 2.1 to generate PhModels. At the initial step, $3 \mathrm{D}$ conformations of the training set inhibitors were generated by using "3D-QSAR Pharmacophore Generation protocol" with the Best, Fast, and Caesar generating algorithms, respectively, based on the CHARMm-like force field. The conformational-space energy was constrained $\leq 20 \mathrm{kcal} / \mathrm{mol}$ which represented the maximum allowed energy above the global minimum energy. For each training set inhibitor, the number of the diverse $3 \mathrm{D}$ conformations was set to $\leq 255$. All other parameters were set as default values. Following the above rules, the 3D conformations were generated, and then we can construct the PhModel by using "Ligand Pharmacophore Mapping protocol." Each of the ten PhModels using
HypoGen Best, Fast, and Caesar algorithms were generated in this study.

2.4. Combinatorial Fusion. In this study, we use a combinatorial fusion technique to facilitate prediction results selection and combination for improving predictive accuracy in biological activities of inhibitors. The combinatorial fusion we take is analogous to that used in information retrieval [38, 39], pattern recognition [40], molecular similarity searching and structure-based screening [41], and microarray gene expression analysis [42]. These works have demonstrated the following remark [43].

Remark 1. For a set of multiple scoring systems, each with a score function and a rank function, we have that (a) the combination of multiple scoring systems would improve the prediction accuracy only if (1) each of the systems has a relatively high performance, and (2) the individual systems are distinctive (or diversified), and (b) rank combination performs better than score combination under certain conditions.

Given an inhibitor and for each prediction result $A$, let $s_{A}$ be a function as the predicted biological activity and it is represented as a real number. We view the function $s_{A}$ as the score function. Since $s_{A}$ only assigns a number not a set of numbers, in this work, no rank function would be used for an inhibitor. Therefore, the rank combination and the rule (b) in Remark 1 are not considered in the study. Suppose we have $m$ prediction results ( $m$ scoring functions). There are combinatorially $2^{m}-1$ combinations for all $m$ individual prediction results $\left(\sum_{k=1}^{m}\left(\begin{array}{c}m \\ k\end{array}\right)=2^{m}-1\right)$ with score functions. The total number of combinations to be considered for predicting biological activity of an inhibitor is $2^{m}-1$. This number of combinations can become huge when the number of prediction results $m$ is large. Moreover, we have to evaluate the predictive power of each combination across all inhibitors. This study would start with combining only two prediction results which still retain fairly good prediction power.

Suppose $m$ prediction results $A_{i}, i=1,2, \ldots, m$, are given with score function $s_{A i}$; there are several different ways of combination. Among others, there are score combination, voting, linear average combination, and weighted combination [38-42]. Voting is computationally simple and better than simple linear combinations when applied to the situation with large number of prediction results. However, a better alternative is to reduce the number of prediction results to a smaller number and then these prediction results are combined. In this paper, we reduce the set of prediction results to those which perform relatively well and then use the rank/score function to decide whether to combine by score. In this paper, we use the rules (a) (1) and (a) (2) stated in Remark 1 as our guiding principle to select prediction results and to decide on the method of combination. After generating each of the ten PhModels by using HypoGen Best, Fast, and Caesar algorithms for training set inhibitors, each of the best PhModel (denoted as Best $t_{\text {train }}$, Fast $t_{\text {train }}$, and Casear $_{\text {train }}$ ) was evaluated by its correlation coefficient of the 


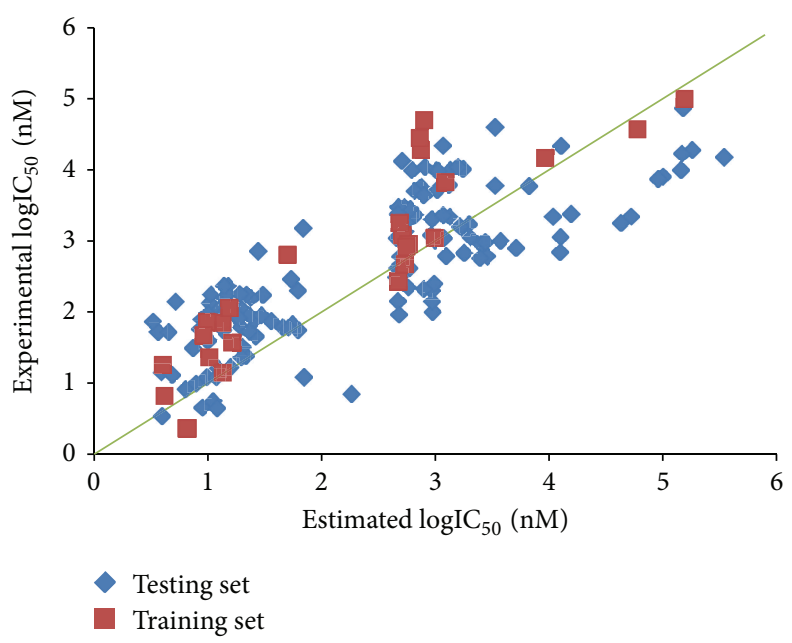

FIGURE 2: The scatter diagram of training set and testing set inhibitors.

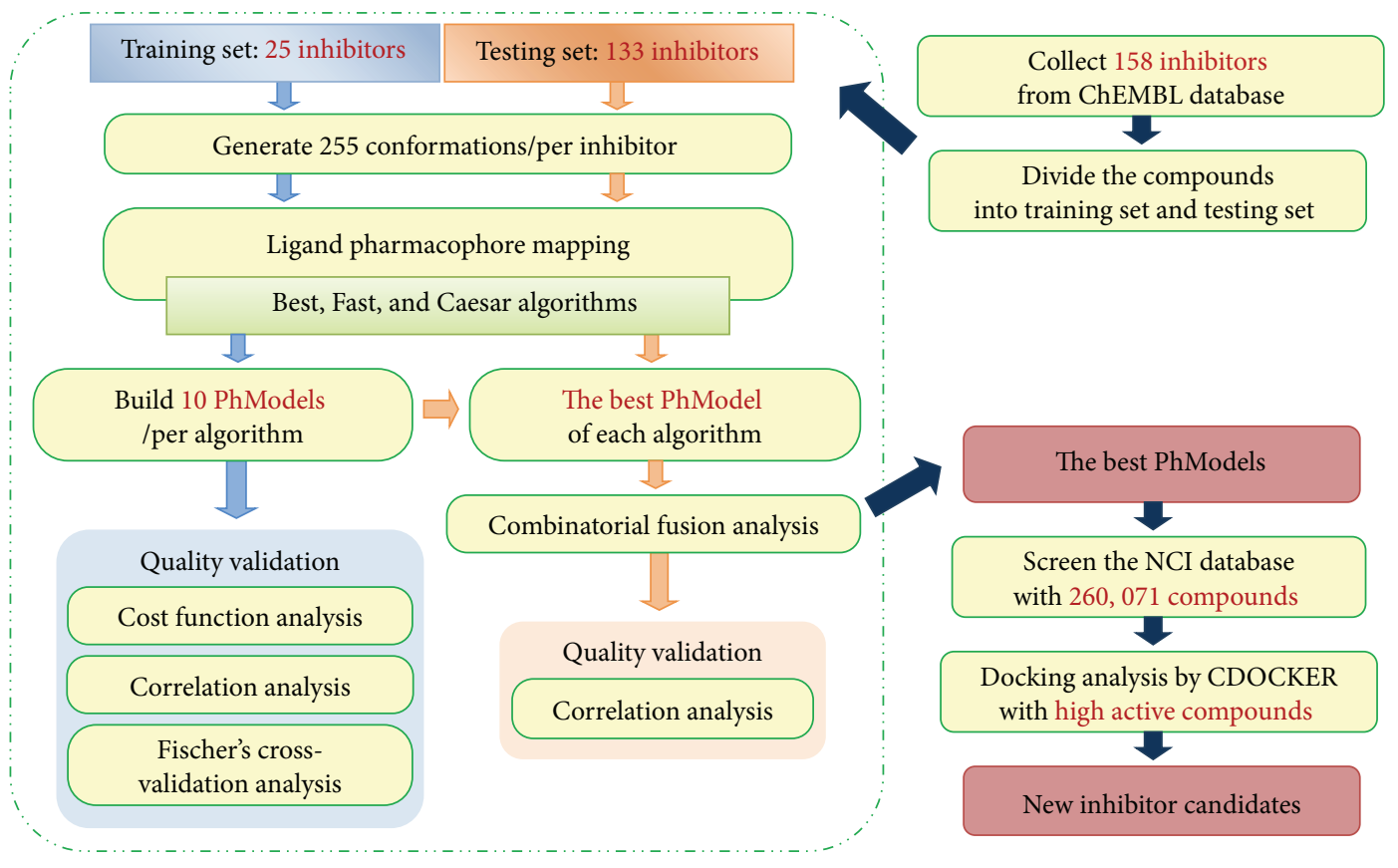

FIgURE 3: The workflow of PhModel generation for Chk2 inhibitors.

training set $\left(r_{\text {train }}\right)$. Then these best PhModels were used to predict the biological activities of testing set inhibitors by using HypoGen Best, Fast, and Caesar algorithms. Therefore, there are nine prediction results (denoted as $Z_{\text {train }} \times Z_{\text {test }}$, $Z=\{$ Best, Fast, Caesar $\}$, that is, Best ${ }_{\text {train }}$ Best $_{\text {test }}$ ) generated for testing set inhibitors. Using data fusion, results from various prediction results are combined to obtain predictions with larger accuracy rate. The diversity rank/score function is used to select the most suitable prediction results for combination. If these three best PhModels were selected, there are nine prediction results and then there are $2^{9}-$ $1=511$ combinations. According to the rule (a) (1) in Remark 1, the $r_{\text {train }}$ of Casear $r_{\text {train }}$ is far less than those of Best $_{\text {train }}$ and Fast $t_{\text {train }}$ (Table 1); then, the Casear ${ }_{\text {train }}$ was not considered in the combinations. Therefore, there are six prediction results $\left(Z_{1 \text { train }} \times Z_{2 \text { test }}, Z_{1}=\{\right.$ Best, Fast $\}$ and $Z_{2}=\{$ Best, Fast, Caesar $\}$ ) and $2^{6}-1=63$ combinations. A special diversity rank/score graph was used to choose the best discriminating prediction results for further combination.

For an inhibitor $p_{i}$ in the testing set $P=\left\{p_{1}, p_{2}, \ldots, p_{t}\right\}$ and the pair of prediction results $A$ and $B$, the diversity score function $d_{i}(A, B)$ is defined as $d_{i}(A, B)=\sum\left|s_{A}-s_{B}\right|$. When there are $q$ prediction results selected (in this study, $q=$ 6), there are $\left(\begin{array}{l}q \\ 2\end{array}\right)=q(q-1) / 2$ (in this study, the number is 15$)$ diversity score functions. If we let $i$ vary and fix the prediction result pair $(A, B)$, then $d_{i}(A, B)$ is the diversity score function $s_{(A, B)}$ from $P=\left\{p_{1}, p_{2}, \ldots, p_{t}\right\}$. Sorting $s_{(A, B)}$ into descending order would lead to the diversity 
TABLE 1: Experimental and estimated $\mathrm{IC}_{50}$ values of training set inhibitors.

\begin{tabular}{|c|c|c|c|c|}
\hline \multirow{2}{*}{ CHEMBL ID } & \multirow{2}{*}{ Experimental $\mathrm{IC}_{50}(\mathrm{nM})$} & \multicolumn{3}{|c|}{ Estimated $\mathrm{IC}_{50}(\mathrm{nM})$} \\
\hline & & Best $_{\text {train }}$ & Fast $_{\text {train }}$ & Caesar $_{\text {train }}$ \\
\hline CHEMBL195041 & 2.3 & 15 & 9.9 & 1129 \\
\hline CHEMBL193990 & 6.6 & 6.8 & 6.2 & 942 \\
\hline CHEMBL248935 & 14 & 20 & 20 & 833 \\
\hline CHEMBL195320 & 18 & 8.5 & 6.2 & 942 \\
\hline CHEMBL176164 & 23 & 19 & 23 & 1151 \\
\hline CHEMBL250765 & 37 & 30 & 22 & 950 \\
\hline CHEMBL362677 & 47 & 23 & 23 & 1153 \\
\hline CHEMBL249959 & 70 & 110 & 20 & 1000 \\
\hline CHEMBL250992 & 72 & 47 & 6.9 & 72 \\
\hline CHEMBL251155 & 110 & 220 & 23 & 756 \\
\hline CHEMBL588536 & 270 & 670 & 790 & 78578 \\
\hline CHEMBL400772 & 470 & 2200 & 268 & 231 \\
\hline CHEMBL367390 & 640 & 2000 & 2237 & 1028 \\
\hline CHEMBL608262 & 830 & 1200 & 1456 & 94262 \\
\hline CHEMBL401105 & 900 & 1000 & 235 & 20 \\
\hline CHEMBL176115 & 1100 & 970 & 1044 & 1449 \\
\hline CHEMBL253542 & 1200 & 1100 & 189 & 3.8 \\
\hline CHEMBL592490 & 1800 & 860 & 1275 & 93360 \\
\hline CHEMBL589090 & 6700 & 1700 & 1419 & 3561 \\
\hline CHEMBL199299 & 15000 & 22000 & 233 & 1745 \\
\hline CHEMBL251629 & 19000 & 3600 & 615 & 411 \\
\hline CHEMBL259084 & 28000 & 6800 & 31827 & 5300 \\
\hline CHEMBL251628 & 37000 & 63000 & 1360 & 24786 \\
\hline CHEMBL438485 & 50000 & 16000 & 320 & 243 \\
\hline CHEMBL589501 & 100000 & 160000 & 48276 & 96926 \\
\hline Correlation coefficient $\left(r_{\text {train }}\right)$ & & 0.955 & 0.840 & 0.238 \\
\hline
\end{tabular}

rank function $r_{(A, B)}$. Consequently, the diversity rank/score function $f_{(A, B)}$ is defined as $f_{(A, B)}=\left(s_{(A, B)} \circ r_{(A, B)}^{-1}\right)(j)=$ $s_{(A, B)}\left(r_{(A, B)}^{-1}(j)\right)$, where $j$ is in $T=\{1,2,3, \ldots, t\}$. We note that the set $T$ is different from the set $P$ which is the testing set considered. The set $T$ is used as the index set for the diversity rank function value and $|T|=t$ is indeed the cardinality of $P$. The diversity rank/score function $f_{(A, B)}$ so defined exhibits the diversity trend of the prediction result pair $(A, B)$ across the whole spectrum of input set of $t$ inhibitors and is independent of the specific inhibitor under study. For two prediction results $A$ and $B$, the graph of the diversity rank/score function $f_{(A, B)}(j)$ is called the diversity rank/score graph. This study aims to examine all the $q(q-1) / 2$ diversity rank/score graphs to see which pair of prediction results would give the larger diversity measurement according to the rule (a) (2) in Remark 1.

2.5. Database Screen. After examining 15 diversity rank/score graphs, the PhModels $A$ and $B$ determined from the best prediction result pair were used to screen the NCI database for new Chk2 inhibitor candidates. Under the PhModel, pharmacophore hypothesis screening can be used to screen small molecule database to retrieve the compounds as potential inhibitors that fit the pharmacophoric features.
In this study, the "Search 3D Database protocol" with the Best/Fast/Casear Search option in Accelrys Discovery Studio 2.1 was employed to search the NCI database with 260,071 compounds. We could filter out and select the compounds in the NCI database based on the estimated activity and chemical features of PhModel.

2.6. Molecular Docking. After the database screening approach, the selected compounds can be further estimated according to the interaction energy between a receptor and a ligand through the molecular docking approach. In this study, selected compounds in the NCI database were docked into Chk2 active sites by CDOCKER docking program, and then their CDOCKER interaction energies were estimated. Finally, new potential candidates were retrieved from the NCI database with high interaction energy. The workflow of database screening and molecular docking approach was shown in Figure 4.

\section{Results}

3.1. PhModel Generation Results. Each of the ten PhModels using 25 training set inhibitors and HypoGen Best, Fast, and Caesar algorithms was generated by selecting hydrogen bond 


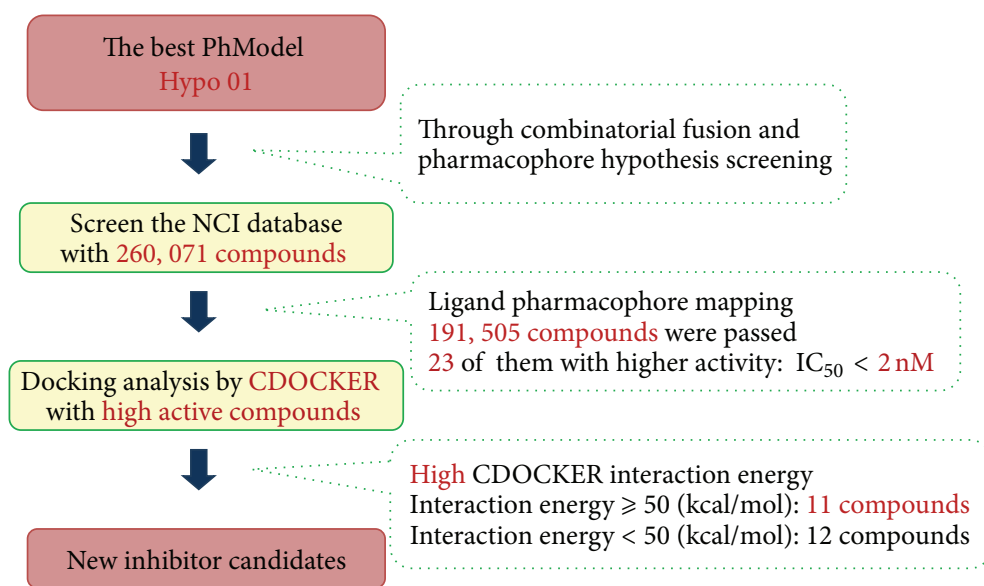

FIGURE 4: The workflow of database screening and molecular docking approach for new Chk2 inhibitor candidates.

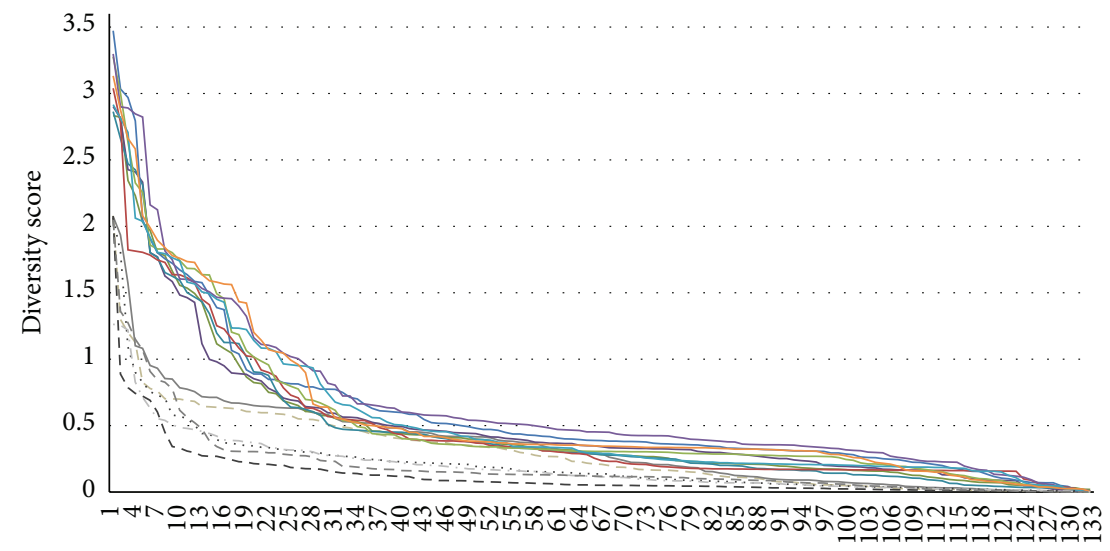

Testing set inhibitors

$\begin{array}{lll}-\mathrm{BB}+\mathrm{BC} & -\mathrm{BC}+\mathrm{BF} & -\mathrm{BF}+\mathrm{FC} \\ -\mathrm{BB}+\mathrm{BF} & -\mathrm{BC}+\mathrm{FB} & -\mathrm{BF}+\mathrm{FF} \\ -\mathrm{BB}+\mathrm{FB} & -\mathrm{BC}+\mathrm{FC} & \cdots \cdot \mathrm{FB}+\mathrm{FC} \\ -\mathrm{BB}+\mathrm{FC} & -\mathrm{BC}+\mathrm{FF} & --\mathrm{FB}+\mathrm{FF} \\ \mathrm{BB}+\mathrm{FF} & -\mathrm{BF}+\mathrm{FB} & --\mathrm{FC}+\mathrm{FF}\end{array}$

FIGURE 5: The diversity rank/score graphs for 15 combinations of prediction results.

acceptor (A), hydrogen bond donor (D), and hydrophobic $(\mathrm{H})$ and hydrophobic aromatic (HYAR) features. Each of the best PhModels, Best ${ }_{\text {train }}$, Fast train $_{\text {, }}$, and Casear ${ }_{\text {train }}$, was evaluated with the best $r_{\text {train }}$, and the predicted biological activities of training set inhibitors and $r_{\text {train }}$ were listed in Table 1, respectively. From Table 1, the Best $t_{\text {train }}$ obtained better $r_{\text {train }}$ of value 0.955 than those by Fast $t_{\text {train }}$ and Casear ${ }_{\text {train }}$. Moreover, the $r_{\text {train }}$ of Casear ${ }_{\text {train }}$ is far less than those of Best $_{\text {train }}$ and Fast train. Hence, HypoGen Best algorithm was used individually to generate the PhModels for most of target genes in the past. According to rule (a) (1) in Remark 1, the Casear $_{\text {train }}$ was not considered to be used for the prediction of testing set inhibitors.

3.2. Correlation Analysis of Testing Set Inhibitors. The testing set inhibitors were predicted by Best $t_{\text {train }}$ and Fast $t_{\text {train }}$ with HypoGen Best, Fast, and Caesar algorithms. Therefore, there are six prediction results, Best $t_{\text {train }} B$ st $_{\text {test }}$ (denoted as $\mathrm{BB}$ ), Best $t_{\text {train }}$ Fast $_{\text {test }}$ (denoted as BF), Best train Casear $_{\text {test }}$ (denoted as BC), Fasr ${ }_{\text {train }}$ Best $_{\text {test }}$ (denoted as FB), Fast train $_{\text {Fast }}$ test $_{\text {(denoted }}$ as FF), and Fast train Casear $_{\text {test }}$ (denoted as FC), for testing set inhibitors. The predicted biological activities of testing set inhibitors and $r_{\text {test }}$ by these six prediction results were listed in Table 2, respectively. From Table 2, for the Best train, $_{\text {, the }}$ best $r_{\text {test }}$ of value 0.81 was achieved by the Best $t_{\text {train }}$ Best test ; for the Fast train, the best $r_{\text {test }}$ of value 0.728 was achieved by the Fast ${ }_{\text {train }}$ Fast $_{\text {test }}$. However, the Best $t_{\text {train }}$ Best $_{\text {test }}$ obtained the best $r_{\text {test }}$ in overall; moreover, the prediction results in the Best $_{\text {train }}$ all outperform those in the Fast $t_{\text {train }}$.

3.3. Combinatorial Fusion Analysis. Under the six prediction results, the diversity score function $d_{i}(A, B)$ was calculated for each testing set inhibitor by a pair of prediction results $(A, B)$. There are 15 diversity score functions $s_{(A, B)}$ that were 
TABLE 2: Experimental and estimated $\mathrm{IC}_{50}$ values of testing set inhibitors.

\begin{tabular}{|c|c|c|c|c|c|c|c|c|}
\hline \multirow{3}{*}{ CHEMBL ID } & \multirow{3}{*}{$\begin{array}{l}\text { Experimental } \\
\mathrm{IC}_{50}(\mathrm{nM})\end{array}$} & \multicolumn{7}{|c|}{ Estimated $\mathrm{IC}_{50}(\mathrm{nM})$} \\
\hline & & \multicolumn{3}{|c|}{ Best $_{\text {train }}$} & \multicolumn{3}{|c|}{ Fast $_{\text {train }}$} & \multirow{2}{*}{$\begin{array}{l}\text { Best }_{\text {train }} \text { Best }_{\text {test }}+ \\
\text { Fast }_{\text {train }} \text { Fast }_{\text {test }}\end{array}$} \\
\hline & & Best $_{\text {test }}$ & Fast $_{\text {test }}$ & Caesar $_{\text {test }}$ & Best $_{\text {test }}$ & Fast $_{\text {test }}$ & Caesar $_{\text {test }}$ & \\
\hline CHEMBL195177 & 3.4 & 3.9 & 5.2 & 5.1 & 14.8 & 6.2 & 12.3 & 6.2 \\
\hline CHEMBL359881 & 4.4 & 12.0 & 46.1 & 42.3 & 17.3 & 22.5 & 29.4 & 22.5 \\
\hline CHEMBL179717 & 4.5 & 9.0 & 42.1 & 43.2 & 14.3 & 21.9 & 29.3 & 21.9 \\
\hline CHEMBL175553 & 5.5 & 11.2 & 57.8 & 43.1 & 17.6 & 20.5 & 29.1 & 20.5 \\
\hline CHEMBL192161 & 7 & 183.4 & 74.6 & 36.7 & 258.7 & 253.9 & 291.4 & 253.9 \\
\hline CHEMBL191969 & 8.2 & 6.4 & 15.3 & 14.3 & 10.5 & 9.4 & 13.5 & 9.4 \\
\hline CHEMBL175472 & 9.8 & 7.9 & 48.4 & 9.9 & 12.4 & 22.5 & 29.1 & 22.5 \\
\hline CHEMBL361378 & 12 & 9.9 & 48.1 & 43.7 & 14.7 & 21.7 & 29.3 & 21.7 \\
\hline CHEMBL362255 & 12 & 11.9 & 55.4 & 42.3 & 15.5 & 22.9 & 29.4 & 22.9 \\
\hline CHEMBL369254 & 12 & 70.2 & 51.3 & 45.6 & 38.0 & 23.7 & 31.5 & 23.7 \\
\hline CHEMBL364978 & 13 & 4.8 & 4.9 & 5.1 & 13.5 & 6.5 & 12.3 & 6.5 \\
\hline CHEMBL195846 & 14 & 3.9 & 5.0 & 5.1 & 12.8 & 6.2 & 12.3 & 6.2 \\
\hline CHEMBL179583 & 16 & 12.2 & 48.5 & 43.1 & 13.4 & 23.2 & 28.9 & 23.2 \\
\hline CHEMBL178972 & 17 & 15.9 & 52.5 & 43.1 & 18.0 & 23.3 & 29.1 & 23.3 \\
\hline CHEMBL250360 & 23 & 19.8 & 46.8 & 43.7 & 17.6 & 21.7 & 29.4 & 21.7 \\
\hline CHEMBL175879 & 24 & 21.6 & 57.0 & 42.3 & 24.0 & 23.2 & 29.2 & 23.2 \\
\hline CHEMBL179267 & 31 & 7.4 & 63.5 & 42.8 & 20.5 & 21.2 & 29.4 & 21.2 \\
\hline CHEMBL192022 & 32 & 20.3 & 47.5 & 42.6 & 23.9 & 22.4 & 29.4 & 22.4 \\
\hline CHEMBL250158 & 39 & 10.1 & 20.4 & 43.7 & 19.1 & 21.5 & 29.3 & 21.5 \\
\hline CHEMBL363339 & 41 & 10.1 & 59.8 & 42.2 & 18.1 & 24.0 & 29.5 & 24.0 \\
\hline CHEMBL250555 & 45 & 26.3 & 48.2 & 42.9 & 24.5 & 22.7 & 29.4 & 22.7 \\
\hline CHEMBL250359 & 52 & 3.7 & 5.2 & 3.5 & 20.6 & 7.0 & 28.8 & 7.0 \\
\hline CHEMBL251585 & 52 & 4.5 & 3.0 & 3.1 & 11.9 & 4.9 & 10.7 & 4.9 \\
\hline CHEMBL398529 & 53 & 23.0 & 48.4 & 43.5 & 21.4 & 22.4 & 29.4 & 22.4 \\
\hline CHEMBL178971 & 55 & 62.4 & 44.9 & 43.1 & 41.7 & 22.1 & 29.3 & 22.1 \\
\hline CHEMBL427879 & 55 & 13.7 & 45.4 & 42.4 & 16.9 & 19.9 & 29.5 & 19.9 \\
\hline CHEMBL250963 & 57 & 8.6 & 44.1 & 42.9 & 17.8 & 21.5 & 27.2 & 21.5 \\
\hline CHEMBL251170 & 60 & 51.3 & 45.3 & 43.1 & 26.3 & 21.5 & 29.4 & 21.5 \\
\hline CHEMBL250759 & 61 & 45.6 & 47.4 & 43.3 & 36.6 & 23.2 & 29.5 & 23.2 \\
\hline CHEMBL367263 & 61 & 19.7 & 50.3 & 9.6 & 17.3 & 23.9 & 29.1 & 23.9 \\
\hline CHEMBL250159 & 67 & 55.7 & 45.3 & 43.1 & 25.7 & 17.2 & 29.4 & 17.2 \\
\hline CHEMBL398467 & 70 & 11.4 & 46.5 & 42.7 & 21.0 & 20.4 & 29.4 & 20.4 \\
\hline CHEMBL250796 & 73 & 3.3 & 3.4 & 4.2 & 14.7 & 6.0 & 14.4 & 6.0 \\
\hline CHEMBL250957 & 74 & 36.1 & 44.9 & 43.7 & 30.5 & 20.4 & 29.5 & 20.4 \\
\hline CHEMBL206609 & 77 & 25.9 & 51.0 & 44.0 & 9.6 & 16.3 & 17.8 & 16.3 \\
\hline CHEMBL400755 & 78 & 8.8 & 26.6 & 43.0 & 12.9 & 22.5 & 29.4 & 22.5 \\
\hline CHEMBL249569 & 80 & 11.1 & 48.3 & 43.3 & 17.0 & 22.9 & 28.0 & 22.9 \\
\hline CHEMBL193397 & 81 & 9.9 & 43.8 & 42.8 & 14.5 & 21.2 & 28.4 & 21.2 \\
\hline CHEMBL438868 & 82 & 18.9 & 42.0 & 43.1 & 13.1 & 19.0 & 29.3 & 19.0 \\
\hline CHEMBL249566 & 86 & 17.6 & 48.8 & 43.1 & 23.5 & 22.8 & 29.6 & 22.8 \\
\hline CHEMBL249345 & 90 & 23.2 & 47.6 & 43.0 & 20.9 & 20.0 & 25.0 & 20.0 \\
\hline CHEMBL399146 & 90 & 29.8 & 47.9 & 42.7 & 28.4 & 22.1 & 29.3 & 22.1 \\
\hline CHEMBL602931 & 92 & 483.6 & 560.1 & 506.8 & 645.9 & 594.0 & 588.2 & 594.0 \\
\hline CHEMBL249347 & 95 & 10.1 & 46.3 & 43.1 & 27.2 & 20.1 & 29.2 & 20.1 \\
\hline CHEMBL193476 & 100 & 951.1 & 914.5 & 925.8 & 2435.2 & 1027.4 & 1981.9 & 1027.4 \\
\hline
\end{tabular}


TABle 2: Continued.

\begin{tabular}{|c|c|c|c|c|c|c|c|c|}
\hline \multirow{3}{*}{ CHEMBL ID } & \multirow{3}{*}{$\begin{array}{l}\text { Experimental } \\
\mathrm{IC}_{50}(\mathrm{nM})\end{array}$} & \multicolumn{7}{|c|}{ Estimated $\mathrm{IC}_{50}(\mathrm{nM})$} \\
\hline & & \multicolumn{3}{|c|}{ Best $_{\text {train }}$} & \multicolumn{3}{|c|}{ Fast $_{\text {train }}$} & \multirow{2}{*}{$\begin{array}{l}\text { Best }_{\text {train }} \text { Best }_{\text {test }}+ \\
\text { Fast }_{\text {train }} \text { Fast }_{\text {test }}\end{array}$} \\
\hline & & Best $_{\text {test }}$ & Fast $_{\text {test }}$ & Caesar ${ }_{\text {test }}$ & Best $_{\text {test }}$ & Fast $_{\text {test }}$ & Caesar $_{\text {test }}$ & \\
\hline CHEMBL250361 & 100 & 14.2 & 6.6 & 14.5 & 14.9 & 20.9 & 29.6 & 20.9 \\
\hline CHEMBL248934 & 109 & 20.0 & 52.5 & 43.3 & 14.0 & 22.4 & 29.4 & 22.4 \\
\hline CHEMBL249750 & 110 & 12.7 & 49.3 & 43.5 & 20.7 & 21.6 & 29.3 & 21.6 \\
\hline CHEMBL208463 & 133 & 10.4 & 46.0 & 41.0 & 968.6 & 2768.3 & 2670.7 & 2768.3 \\
\hline CHEMBL250566 & 140 & 5.2 & 17.3 & 26.3 & 18.4 & 20.9 & 29.6 & 20.9 \\
\hline CHEMBL251256 & 140 & 936.4 & 2453.5 & 2240.6 & 192.6 & 215.1 & 215.5 & 215.1 \\
\hline CHEMBL437331 & 142 & 471.8 & 521.6 & 450.6 & 64.2 & 222.1 & 60.7 & 222.1 \\
\hline CHEMBL249541 & 157 & 23.8 & 42.5 & 43.0 & 16.0 & 18.8 & 29.3 & 18.8 \\
\hline CHEMBL249776 & 158 & 13.9 & 47.2 & 43.7 & 16.7 & 20.9 & 29.4 & 20.9 \\
\hline CHEMBL249350 & 174 & 30.6 & 51.2 & 43.4 & 22.5 & 23.3 & 29.4 & 23.3 \\
\hline CHEMBL249546 & 176 & 10.6 & 47.3 & 42.8 & 17.9 & 21.0 & 29.4 & 21.0 \\
\hline CHEMBL251364 & 176 & 21.7 & 43.9 & 43.1 & 17.8 & 19.7 & 29.1 & 19.7 \\
\hline CHEMBL399933 & 180 & 14.8 & 45.0 & 43.5 & 20.8 & 18.9 & 29.4 & 18.9 \\
\hline CHEMBL400287 & 180 & 19.3 & 45.5 & 43.5 & 21.5 & 19.8 & 29.4 & 19.8 \\
\hline CHEMBL175780 & 200 & 61.7 & 47.5 & 42.3 & 36.0 & 21.9 & 29.5 & 21.9 \\
\hline CHEMBL176326 & 200 & 935.6 & 926.3 & 913.6 & 1896.0 & 986.2 & 1980.7 & 986.2 \\
\hline CHEMBL590335 & 210 & 791.5 & 721.8 & 807.4 & 616.3 & 639.0 & 644.7 & 639.0 \\
\hline CHEMBL398561 & 220 & 575.1 & 926.2 & 571.5 & 209.1 & 278.3 & 287.9 & 278.3 \\
\hline CHEMBL249777 & 231 & 15.0 & 45.7 & 42.5 & 25.5 & 21.7 & 29.4 & 21.7 \\
\hline CHEMBL442282 & 233 & 13.9 & 46.9 & 42.3 & 21.5 & 22.5 & 29.4 & 22.5 \\
\hline CHEMBL195599 & 250 & 981.5 & 908.0 & 925.8 & 2266.7 & 1057.6 & 1981.9 & 1057.6 \\
\hline CHEMBL176015 & 290 & 54.1 & 52.8 & 54.4 & 24.0 & 29.3 & 28.0 & 29.3 \\
\hline CHEMBL251284 & 310 & 484.8 & 429.7 & 533.7 & 189.6 & 196.8 & 217.4 & 196.8 \\
\hline CHEMBL600441 & 310 & 454.6 & 559.9 & 516.5 & 300.5 & 513.5 & 254.1 & 513.5 \\
\hline CHEMBL599581 & 410 & 594.7 & 496.6 & 509.1 & 506.1 & 252.9 & 299.2 & 252.9 \\
\hline CHEMBL592784 & 420 & 462.2 & 492.0 & 475.1 & 216.7 & 203.8 & 198.3 & 203.8 \\
\hline CHEMBL1197465 & 580 & 2492.8 & 8163.9 & 5925.9 & 995.1 & 896.8 & 488.9 & 896.8 \\
\hline CHEMBL590809 & 600 & 492.4 & 539.0 & 534.3 & 816.4 & 536.2 & 549.3 & 536.2 \\
\hline CHEMBL1197456 & 610 & 2871.8 & 7537.6 & 6733.2 & 615.7 & 4139.2 & 3514.6 & 4139.2 \\
\hline CHEMBL590637 & 610 & 1251.9 & 1786.7 & 1121.1 & 2379.0 & 1650.9 & 1262.3 & 1650.9 \\
\hline CHEMBL591518 & 680 & 1797.9 & 1804.0 & 1516.5 & 6075.0 & 4714.4 & 2726.5 & 4714.4 \\
\hline CHEMBL598973 & 700 & 12585.6 & 151896.0 & 84151.4 & 1047.3 & 396.5 & 1318.1 & 396.5 \\
\hline CHEMBL251368 & 710 & 27.7 & 45.9 & 43.8 & 13.4 & 21.2 & 29.1 & 21.2 \\
\hline CHEMBL1197303 & 800 & 5153.6 & 36481.1 & 6594.4 & 1277.8 & 681.9 & 4077.9 & 681.9 \\
\hline CHEMBL1197320 & 890 & 2537.8 & 7191.1 & 6002.7 & 1559.4 & 517.5 & 420.0 & 517.5 \\
\hline CHEMBL1197528 & 960 & 2752.7 & 7737.1 & 5925.9 & 765.7 & 654.9 & 559.0 & 654.9 \\
\hline CHEMBL215803 & 1000 & 3760.6 & 140257.0 & 74847.0 & 9672.7 & 50053.5 & 49263.9 & 50053.5 \\
\hline CHEMBL253324 & 1000 & 996.2 & 2416.5 & 603.1 & 264.7 & 553.1 & 272.4 & 553.1 \\
\hline CHEMBL589347 & 1100 & 458.3 & 560.2 & 482.3 & 209.7 & 299.1 & 196.7 & 299.1 \\
\hline CHEMBL604784 & 1100 & 1188.4 & 1365.6 & 1205.7 & 2305.3 & 1962.3 & 1307.9 & 1962.3 \\
\hline CHEMBL1197529 & 1120 & 2047.4 & 11678.5 & 8090.0 & 3368.8 & 3648.8 & 3659.9 & 3648.8 \\
\hline CHEMBL1197326 & 1130 & 12645.5 & 45428.8 & 7432.7 & 1138.2 & 465.0 & 416.0 & 465.0 \\
\hline CHEMBL176041 & 1200 & 925.0 & 906.8 & 913.6 & 1933.6 & 1040.0 & 1980.7 & 1040.0 \\
\hline CHEMBL590079 & 1350 & 548.9 & 548.5 & 550.6 & 1000.9 & 860.3 & 855.1 & 860.3 \\
\hline CHEMBL605083 & 1400 & 489.2 & 613.8 & 554.4 & 1224.9 & 1401.0 & 1345.6 & 1401.0 \\
\hline CHEMBL175481 & 1500 & 69.2 & 57.7 & 49.2 & 1853.9 & 1526.1 & 1852.1 & 1526.1 \\
\hline
\end{tabular}


TABLE 2: Continued.

\begin{tabular}{|c|c|c|c|c|c|c|c|c|}
\hline \multirow{3}{*}{ CHEMBL ID } & \multirow{3}{*}{$\begin{array}{l}\text { Experimental } \\
\mathrm{IC}_{50}(\mathrm{nM})\end{array}$} & \multicolumn{7}{|c|}{ Estimated $\mathrm{IC}_{50}(\mathrm{nM})$} \\
\hline & & \multicolumn{3}{|c|}{ Best $_{\text {train }}$} & \multicolumn{3}{|c|}{ Fast $_{\text {train }}$} & \multirow{2}{*}{$\begin{array}{l}\text { Best }_{\text {train }} \text { Best }_{\text {test }}+ \\
\text { Fast }_{\text {train }} \text { Fast }_{\text {test }}\end{array}$} \\
\hline & & Best $_{\text {test }}$ & Fast $_{\text {test }}$ & Caesar $_{\text {test }}$ & Best $_{\text {test }}$ & Fast $_{\text {test }}$ & Caesar $_{\text {test }}$ & \\
\hline CHEMBL205906 & 1540 & 1696.1 & 1109.3 & 1153.0 & 980.6 & 17655.5 & 937.5 & 17655.5 \\
\hline CHEMBL590808 & 1600 & 1662.5 & 1799.1 & 1709.4 & 51882.2 & 48813.2 & 48302.3 & 48813.2 \\
\hline CHEMBL1170748 & 1700 & 1974.2 & 1940.4 & 1652.8 & 3251.4 & 2734.9 & 407.6 & 2734.9 \\
\hline CHEMBL253541 & 1800 & 43066.9 & 42831.1 & 79622.8 & 1255.9 & 1099.1 & 15566.3 & 1099.1 \\
\hline CHEMBL176554 & 1900 & 572.3 & 7226.3 & 9126.2 & 1096.1 & 3352.6 & 3926.3 & 3352.6 \\
\hline CHEMBL377597 & 2000 & 938.5 & 6719.7 & 5644.6 & 50.4 & 116.9 & 105.4 & 116.9 \\
\hline CHEMBL1170749 & 2200 & 10874.0 & 30873.8 & 3995.6 & 5835.1 & 25044.3 & 1090.5 & 25044.3 \\
\hline CHEMBL590336 & 2200 & 507.8 & 594.0 & 516.4 & 568.9 & 544.3 & 521.1 & 544.3 \\
\hline CHEMBL590807 & 2200 & 52944.6 & 70480.3 & 52639.4 & 44898.4 & 49196.7 & 36195.2 & 49196.7 \\
\hline CHEMBL600868 & 2200 & 1342.8 & 1603.8 & 1312.9 & 7373.6 & 5797.7 & 4864.3 & 5797.7 \\
\hline CHEMBL398759 & 2300 & 666.0 & 2847.2 & 1010.2 & 447.2 & 924.3 & 309.0 & 924.3 \\
\hline CHEMBL604459 & 2300 & 1176.9 & 2299.2 & 1369.3 & 614.2 & 877.8 & 682.5 & 877.8 \\
\hline CHEMBL179383 & 2400 & 15724.9 & 14621.7 & 14257.4 & 4508.5 & 4132.8 & 4023.9 & 4132.8 \\
\hline CHEMBL592489 & 2400 & 469.2 & 494.6 & 486.9 & 204.7 & 240.5 & 208.4 & 240.5 \\
\hline CHEMBL425904 & 2800 & 605.0 & 651.0 & 534.9 & 478.1 & 451.9 & 488.6 & 451.9 \\
\hline CHEMBL150894 & 3000 & 537.8 & 844.9 & 797.6 & 186.8 & 600.2 & 289.0 & 600.2 \\
\hline CHEMBL590793 & 3000 & 475.4 & 2480.4 & 1251.5 & 192.0 & 251.7 & 205.4 & 251.7 \\
\hline CHEMBL600865 & 4400 & 796.9 & 2072.3 & 1223.3 & 198.1 & 261.3 & 228.1 & 261.3 \\
\hline CHEMBL249253 & 5000 & 659.8 & 503.6 & 499.5 & 406.6 & 227.9 & 309.5 & 227.9 \\
\hline CHEMBL587506 & 5200 & 1050.8 & 1293.3 & 1083.2 & 2201.3 & 2162.7 & 1656.0 & 2162.7 \\
\hline CHEMBL204930 & 5800 & 755.5 & 1260.7 & 1105.5 & 47881.6 & 47912.3 & 47868.0 & 47912.3 \\
\hline CHEMBL554900 & 5900 & 6722.8 & 580526.0 & 807309.0 & 745.4 & 428.2 & 47897.1 & 428.2 \\
\hline CHEMBL176276 & 6000 & 3360.2 & 8955.9 & 8476.6 & 2075.6 & 2054.0 & 1970.7 & 2054.0 \\
\hline CHEMBL589091 & 6100 & 1319.5 & 1308.4 & 1172.0 & 579.2 & 603.1 & 600.9 & 603.1 \\
\hline CHEMBL559781 & 7400 & 91783.7 & 822917.0 & 1230010.0 & 414.5 & 6865.5 & 47911.9 & 6865.5 \\
\hline CHEMBL249252 & 8000 & 100671.0 & 38586.8 & 31129.8 & 590.5 & 491.6 & 467.9 & 491.6 \\
\hline CHEMBL589089 & 9800 & 1070.7 & 1321.5 & 1002.7 & 38589.3 & 48136.2 & 41143.2 & 48136.2 \\
\hline CHEMBL217090 & 10000 & 628.8 & 1010.9 & 1548.5 & 390.6 & 451.8 & 910.1 & 451.8 \\
\hline CHEMBL217092 & 10000 & 1030.2 & 1199.3 & 1908.8 & 379.9 & 625.6 & 707.2 & 625.6 \\
\hline CHEMBL382588 & 10000 & 1365.2 & 5880.3 & 5488.7 & 2560.7 & 3993.4 & 3649.4 & 3993.4 \\
\hline CHEMBL590581 & 10000 & 145206.0 & 149922.0 & 108067.0 & 50609.5 & 49348.5 & 48302.3 & 49348.5 \\
\hline CHEMBL242753 & 10300 & 1742.5 & 3393.1 & 1941.1 & 1202.5 & 2613.0 & 1297.3 & 2613.0 \\
\hline CHEMBL398758 & 11000 & 1582.8 & 187965.0 & 1573.6 & 237.0 & 4333.9 & 369.0 & 4333.9 \\
\hline CHEMBL399151 & 11000 & 812.1 & 1263.5 & 2069.9 & 334.5 & 1193.9 & 1271.6 & 1193.9 \\
\hline CHEMBL395080 & 13450 & 513.5 & 484.0 & 458.6 & 198.5 & 188.9 & 183.3 & 188.9 \\
\hline CHEMBL1171533 & 15000 & 349604.0 & 296515.0 & 159368.0 & 26784.5 & 26699.3 & 45506.4 & 26699.3 \\
\hline CHEMBL602729 & 17000 & 148756.0 & 149052.0 & 139465.0 & 224.1 & 324.7 & 229.4 & 324.7 \\
\hline CHEMBL249255 & 19000 & 182486.0 & 42615.8 & 41578.3 & 1698.2 & 616.1 & 683.9 & 616.1 \\
\hline CHEMBL202930 & 21730 & 12828.4 & 11945.6 & 12145.8 & 213.3 & 219.7 & 217.6 & 219.7 \\
\hline CHEMBL589986 & 22000 & 1167.1 & 1337.4 & 1143.5 & 53747.5 & 49155.6 & 49316.8 & 49155.6 \\
\hline CHEMBL251471 & 40000 & 3358.9 & 1946.2 & 2075.7 & 512.2 & 423.7 & 3427.4 & 423.7 \\
\hline CHEMBL560056 & 74000 & 152006.0 & 156723.0 & 208466.0 & 223.2 & 208.1 & 190.4 & 208.1 \\
\hline $\begin{array}{l}\text { Correlation } \\
\text { coefficient }\left(r_{\text {test }}\right)\end{array}$ & & 0.810 & 0.771 & 0.783 & 0.710 & 0.728 & 0.714 & 0.816 \\
\hline
\end{tabular}




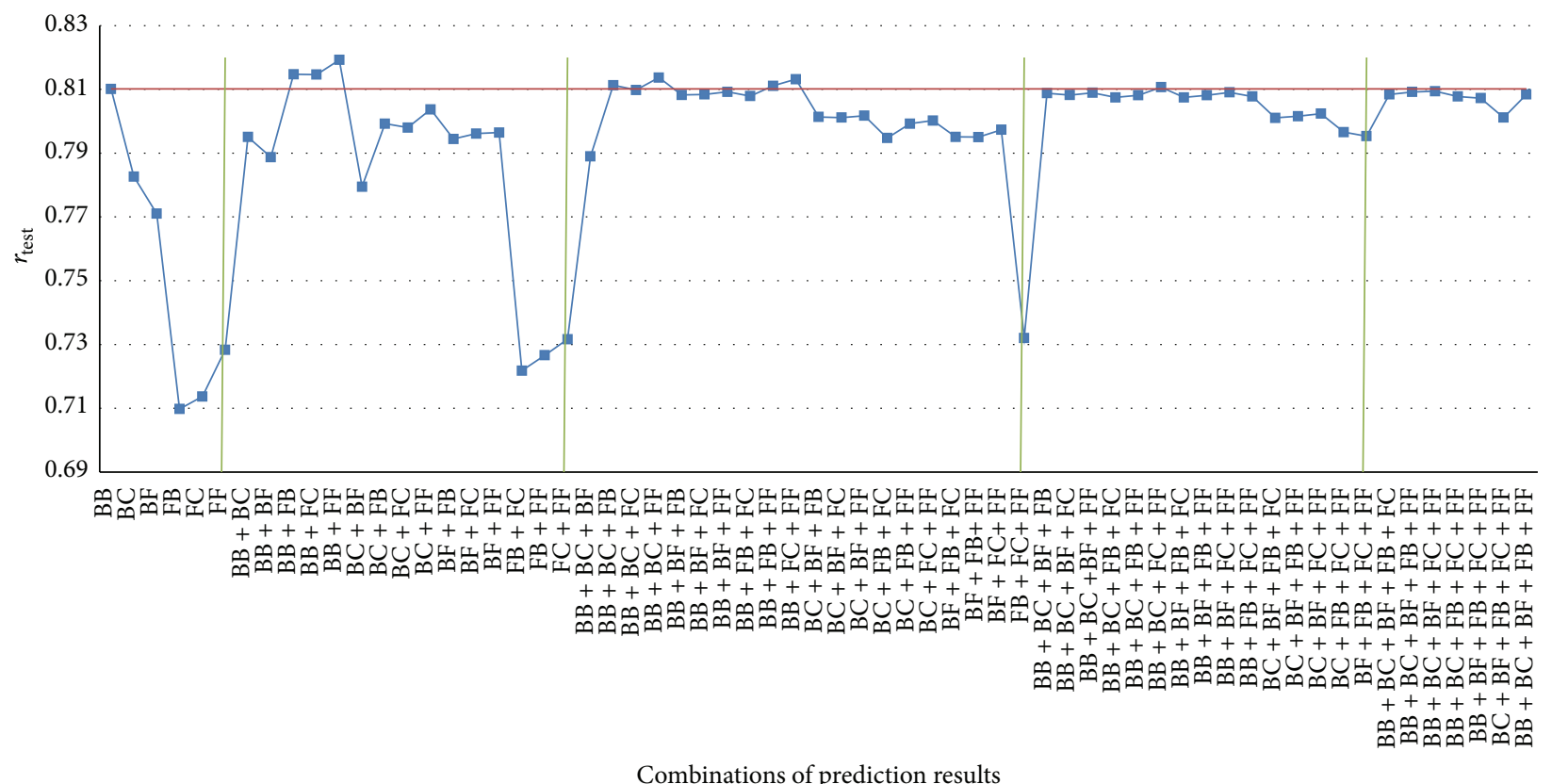

FIgURE 6: The $r_{\text {test }}$ for all of 63 combinations from six prediction results.

performed at first and then these diversity score functions were sorted to become the diversity rank function $r_{(A, B)}$, respectively. Finally, 15 diversity rank/score functions $f_{(A, B)}$ were represented as diversity rank/score graphs shown in Figure 5. Among 15 diversity rank/score graphs, there are several combinations (gray color) that have less diversity scores than those by others, such as $\mathrm{BB}+\mathrm{BC}, \mathrm{BB}+\mathrm{BF}$, and $\mathrm{FB}+\mathrm{FB}$, shown in Figure 5. It means that these combinations may have less $r_{\text {test }}$ than those by others according to rule (a) (2) in Remark 1. In other words, several combinations, such as $\mathrm{BB}+\mathrm{FC}$ (purple color), $\mathrm{BB}+\mathrm{FF}$ (blue color), and BF + FF (orange color), may have larger $r_{\text {test }}$ than those by others due to larger diversity scores. For the six prediction results, all of the 63 combinations were preformed and evaluated by its $r_{\text {test }}$, respectively, as shown in Figure 6. In Figure 6, for 15 pairs of two prediction results, the combinations $\mathrm{BB}+\mathrm{FB}, \mathrm{BB}+\mathrm{FC}$, and $\mathrm{BB}+\mathrm{FF}$ have larger $r_{\text {test }}$ than those by others. Moreover, the combination $\mathrm{BB}+\mathrm{FF}$ has best $r_{\text {test }}$ of value 0.816 among 15 combinations, even for 63 combinations. Besides, the average $r_{\text {test }}$ by the combinations is larger than the individual prediction results. It means that the predictive accuracy for Chk2 inhibitors may be improved by considering the Best ${ }_{\text {train }}$ and Fast train $_{\text {concurrently. }}$

3.4. Database Screen Results. The best PhModels, Best train $_{\text {}}$

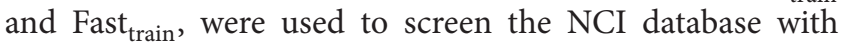
260,071 compounds for new Chk2 inhibitor candidates by using HypoGen Best and Fast algorithms, respectively. The Best $_{\text {train }}$ Best $_{\text {test }}$ and Fast train Fast $_{\text {test }}$ prediction results for NCI database were combined in order to filter out possible false positive candidates. Of the 260,071 compounds, 191,505 passed the screening and best fitted to the chemical features in $3 \mathrm{D}$ space. 23 drug-like compounds that had an estimated $\mathrm{IC}_{50}$
TABLE 3: The 21 drug-like compounds with their estimated $\mathrm{IC}_{50}$ values and CDOCKER interaction energy greater than 37.786 $(\mathrm{kal} / \mathrm{mol})$.

\begin{tabular}{lcc}
\hline Name & Estimated $\mathrm{IC}_{50}(\mathrm{nM})$ & Interaction energy $(\mathrm{kal} / \mathrm{mol})$ \\
\hline NSC 136954 & $\mathbf{1 . 9 8 9}$ & $\mathbf{6 1 . 2 3 9}$ \\
NSC 70804 & $\mathbf{1 . 6 8 2}$ & $\mathbf{5 8 . 9 6 7}$ \\
NSC 158029 & 1.885 & 57.944 \\
NSC 603427 & 1.87 & 56.963 \\
NSC 57782 & 1.6855 & 56.54 \\
NSC 16739 & 1.5385 & 56.342 \\
NSC 720227 & 1.914 & 55.839 \\
NSC 618702 & 1.862 & 55.196 \\
NSC 195178 & 1.7015 & 51.351 \\
NSC 653142 & 1.557 & 51.19 \\
NSC 653143 & 1.577 & 50.055 \\
NSC 32200 & 1.901 & 49.439 \\
NSC 342015 & 1.6515 & 47.327 \\
NSC 343685 & 1.7615 & 46.436 \\
NSC 205750 & 1.875 & 45.542 \\
NSC 96538 & 1.705 & 44.344 \\
NSC 210455 & 1.7935 & 42.258 \\
NSC 314654 & 1.947 & 42.082 \\
NSC 179894 & 1.6135 & 41.707 \\
NSC 91710 & 1.701 & 40.533 \\
NSC 370907 & 1.8785 & 40.502 \\
\hline
\end{tabular}

value of less than $2 \mathrm{nM}$ were studied in a molecular docking study (Figure 4).

3.5. Molecular Docking Results. 23 drug-like compounds along with the training set compounds were docked into the 
TABLE 4: The structures and characteristics of the top 2 compounds.

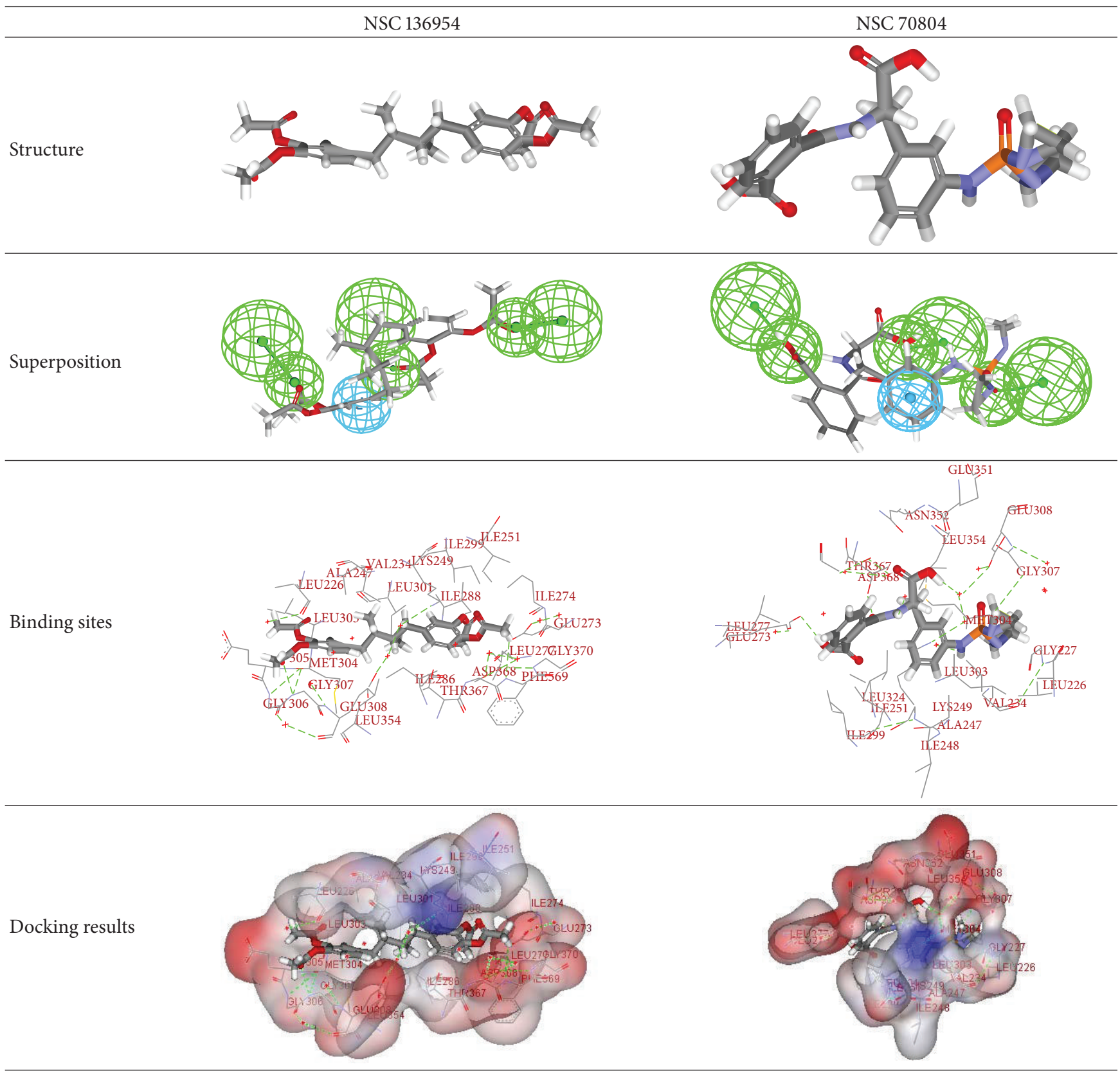

active sites that were defined based on the bound inhibitor, PV1019, in a crystal structure of Chk2 (PDB: 2W7X). We used CDOCKER program to confirm that inhibitor candidates bind to the receptor. CDOCKER uses molecular dynamics (MD) in conjunction with the CHARMm force field to individually dock the compounds into the binding sites. The coordinates of Chk2 from the Chk2/PV1019 crystal structure were used after removing PV1019 and solvent molecules and adding protein hydrogen atoms. After docking each screened compound, its interaction energy value was calculated. The PV1019 was redocked into the Chk2 binding site by the CDOCKER program. Its-CDOCKER interaction energy was calculated by CDOCKER and determined to be $37.786(\mathrm{kal} / \mathrm{mol})$. The 23 drug-like compounds were docked into the Chk2 binding sites. Finally, there are 21 drug-like compounds with CDOCKER interaction energies greater than $37.786(\mathrm{kal} / \mathrm{mol})$. In addition, 11 drug-like compounds had high interaction value greater than $50(\mathrm{kal} / \mathrm{mol})$ (Figure 4$)$ and the top 2 are NSC136954 with $61.239(\mathrm{kal} / \mathrm{mol})$ and NSC70804 with 58.967 (kal/mol), respectively, kept for future characterization as inhibitors. The $21 \mathrm{drug}$-like compounds with their estimated $\mathrm{IC}_{50}$ values and CDOCKER interaction energy greater than $37.786(\mathrm{kal} / \mathrm{mol})$ were shown in Table 3.

The structures and characteristics of the top 2 compounds are given in Table 4, and we can find that some active site residues were identified from the Chk2 complex. The 
interaction sites of NSC136954 were Leu226, Val234, Ala247, Lys249, Ile251, Glu273, Ile274, Leu277, Ile286, Ile288, Ile299, Leu301, Leu303, Met304, Glu305, Gly306, Gly307, Glu308, Leu354, Thr367, Asp368, Phe369, and Gly370. On the other hand, the interaction sites of NSC70804 were Leu226, Leu227, Val234, Ala247, Ile248, Lys249, Ile251, Glu273, Leu277, Ile299, Leu301, Leu303, Met304, Gly307, Glu308, Glu351, Asn352, Leu354, Thr367, and Asp368. Several studies indicated that they are involved in hydrophobic interactions with Val234, Ile251, Leu354, Ile299, and the aliphatic portions of the side chains of Lys249, Thr367, and Asp368, in addition to several interactions of van der Waals or hydrophobic with Leu226, Val234, Leu303, Gly307, Leu354, and the aliphatic portions the side chains of Met304 and Glu308 [10, 11]. Furthermore, the quinazoline was sandwiched between the lipophilic side chains of Val234 and Leu354, with the side chains of Ala247, Leu301, and Leu303 also contributing to a hydrophobic surface surrounding the core and an interaction between the pyrazole and Lys249 is likely to account for the increase in Chk2 potency [12]. And residue Thr367 of Chk2 is a serine in Chk1. Portions of the glycine-rich P-loop in Chk2, which is located directly above the inhibitor, are disordered (residues 229-231), whereas this loop is well defined in the structure of Chk1, and Leu301 in Chk2 corresponds to the "gatekeeper" residue in many kinases, which has been found to form contacts with bound inhibitors and is poorly conserved [44].

\section{Conclusions}

In this study, a novel design strategy for drug design was proposed to apply combinatorial fusion into PhModels and virtual screening techniques. $158 \mathrm{Chk} 2$ inhibitors were divided into the training set and testing set, respectively. For 25 training set inhibitors, three best PhModels, Best ${ }_{\text {train }}$, Fast $_{\text {train }}$, and Casear ${ }_{\text {train }}$, were generated at first, and then six prediction results for 133 testing set inhibitors were used for calculating 15 diversity rank/score functions. Finally, the combination Best $t_{\text {train }}$ Best $_{\text {test }}$ and Fast ${ }_{\text {train }}$ Fast $_{\text {test }}$ prediction results achieved the best $r_{\text {test }}$ of value 0.816 among 63 combinations. Through these approaches, 23 potential Chk2 inhibitors with $\mathrm{IC}_{50}$ value less than $2 \mathrm{nM}$ and interaction energy value larger than $37.786(\mathrm{kal} / \mathrm{mol})$ are retrieved from NCI database. This study can help medicinal chemists to identify or design new Chk2 inhibitors. Besides, the potential inhibitors of Chk 2 retrieved in this work can be estimated by biologists for further study.

\section{Conflict of Interests}

The authors declare that there is no conflict of interests regarding the publication of this paper.

\section{Acknowledgments}

This work was supported in part by the National Science Council of Taiwan (under Grants NSC100-2221-E-182057-MY3) and by Chang Gung Memorial Hospital (Grant CMRPD260033). The authors thank the National Center for
High-Performance Computing for computer time and use of its facilities.

\section{References}

[1] K. M. Culligan, C. E. Robertson, J. Foreman, P. Doerner, and A. B. Britt, "ATR and ATM play both distinct and additive roles in response to ionizing radiation," Plant Journal, vol. 48, no. 6, pp. 947-961, 2006.

[2] J. Yang, Z.-P. Xu, Y. Huang, H. E. Hamrick, P. J. DuerksenHughes, and Y.-N. Yu, "ATM and ATR: sensing DNA damage," World Journal of Gastroenterology, vol. 10, no. 2, pp. 155-160, 2004.

[3] Q. Liu, S. Guntuku, X.-S. Cui et al., "Chk1 is an essential kinase that is regulated by Atr and required for the G2/M DNA damage checkpoint," Genes and Development, vol. 14, no. 12, pp. 14481459, 2000.

[4] C. Tapia-Alveal, T. M. Calonge, and M. J. O’Connell, "Regulation of Chk1," Cell Division, vol. 4, article 8, 2009.

[5] J. Bartek, J. Falck, and J. Lukas, "Chk2 kinase-a busy messenger," Nature Reviews Molecular Cell Biology, vol. 2, no. 12, pp. 877-886, 2001.

[6] J. Li, B. L. Williams, L. F. Haire et al., "Structural and functional versatility of the FHA domain in DNA-damage signaling by the tumor suppressor kinase Chk2," Molecular Cell, vol. 9, no. 5, pp. 1045-1054, 2002.

[7] A. W. Oliver, A. Paul, K. J. Boxall et al., "Trans-activation of the DNA-damage signalling protein kinase Chk2 by T-loop exchange," EMBO Journal, vol. 25, no. 13, pp. 3179-3190, 2006.

[8] Z. Cai, N. H. Chehab, and N. P. Pavletich, "Structure and activation mechanism of the CHK2 DNA damage checkpoint kinase," Molecular Cell, vol. 35, no. 6, pp. 818-829, 2009.

[9] Z. A. Stewart and J. A. Pietenpol, "p53 signaling and cell cycle checkpoints," Chemical Research in Toxicology, vol. 14, no. 3, pp. 243-263, 2001.

[10] G. T. Lountos, A. G. Jobson, J. E. Tropea et al., "Structural characterization of inhibitor complexes with checkpoint kinase 2 (Chk2), a drug target for cancer therapy," Journal of Structural Biology, vol. 176, no. 3, pp. 292-301, 2011.

[11] A. G. Jobson, G. T. Lountos, P. L. Lorenzi et al., "Cellular inhibition of checkpoint kinase $2(\mathrm{Chk} 2)$ and potentiation of camptothecins and radiation by the novel Chk2 inhibitor PV1019 [7nitro-1H-indole-2-carboxylic acid 4-[1-(guanidinohydrazone)ethyl]-phenyl-amide]," Journal of Pharmacology and Experimental Therapeutics, vol. 331, no. 3, pp. 816-826, 2009.

[12] J. J. Caldwell, E. J. Welsh, C. Matijssen et al., "Structure-based design of potent and selective 2-(quinazolin-2-yl)phenol inhibitors of checkpoint kinase 2," Journal of Medicinal Chemistry, vol. 54, no. 2, pp. 580-590, 2011.

[13] G. T. Lountos, A. G. Jobson, J. E. Tropea et al., "X-ray structures of checkpoint kinase 2 in complex with inhibitors that target its gatekeeper-dependent hydrophobic pocket," FEBS Letters, vol. 585, no. 20, pp. 3245-3249, 2011.

[14] S. Hilton, S. Naud, J. J. Caldwell et al., "Corrigendum to 'Identification and characterisation of 2-aminopyridine inhibitors of checkpoint kinase 2"' Bioorganic and Medicinal Chemistry, vol. 18, no. 12, p. 4591, 2010.

[15] E. M. Rosen, S. Fan, R. G. Pestell, and I. D. Goldberg, "BRCA1 gene in breast cancer," Journal of Cellular Physiology, vol. 196, no. 1, pp. 19-41, 2003. 
[16] E. S. Yang and F. Xia, "BRCA1 16 years later: DNA damageinduced BRCA1 shuttling," FEBS Journal, vol. 277, no. 15, pp. 3079-3085, 2010.

[17] M. Gupta, S. Gupta, H. Dureja, and A. K. Madan, "Superaugmented eccentric distance sum connectivity indices: Novel highly discriminating topological descriptors for QSAR/QSPR," Chemical Biology and Drug Design, vol. 79, no. 1, pp. 38-52, 2012.

[18] F. A. Pasha, M. Muddassar, and S. Joo Cho, "Molecular docking and 3D QSAR studies of Chk2 inhibitors," Chemical Biology and Drug Design, vol. 73, no. 3, pp. 292-300, 2009.

[19] H. Kubinyi, G. Folkers, and Y. C. Martin, 3D QSAR in Drug Design, Springer, 2002.

[20] Y.-K. Jiang, "Molecular docking and 3D-QSAR studies on $\beta$ phenylalanine derivatives as dipeptidyl peptidase IV inhibitors," Journal of Molecular Modeling, vol. 16, no. 7, pp. 1239-1249, 2010.

[21] R. R. S. Pissurlenkar, M. S. Shaikh, and E. C. Coutinho, "3DQSAR studies of Dipeptidyl peptidase IV inhibitors using a docking based alignment," Journal of Molecular Modeling, vol. 13, no. 10, pp. 1047-1071, 2007.

[22] W. Sippl, 3D-QSAR-Applications, Recent Advances, and Limitations. Recent Advances in QSAR Studies, Springer, 2010.

[23] A. Lauria, M. Ippolito, M. Fazzari et al., "IKK- $\beta$ inhibitors: an analysis of drug-receptor interaction by using Molecular Docking and Pharmacophore 3D-QSAR approaches," Journal of Molecular Graphics and Modelling, vol. 29, no. 1, pp. 72-81, 2010.

[24] S. John, S. Thangapandian, M. Arooj, J. C. Hong, K. D. Kim, and K. W. Lee, "Development, evaluation and application of 3D QSAR Pharmacophore model in the discovery of potential human renin inhibitors," BMC Bioinformatics, vol. 12, pp. 1-14, 2011.

[25] H. Kubinyi and Comparative Molecular Field Analysis (CoMFA), Handbook of Chemoinformatics: From Data To Knowledge in 4 Volumes, Wiley, 2008.

[26] K. W. Lee and J. M. Briggs, "Comparative molecular field analysis (CoMFA) study of epothilones-tubulin depolymerization inhibitors: pharmacophore development using 3D QSAR methods," Journal of Computer-Aided Molecular Design, vol. 15, no. 1, pp. 41-55, 2001.

[27] S. Durdagi, T. Mavromoustakos, and M. G. Papadopoulos, “3D QSAR CoMFA/CoMSIA, molecular docking and molecular dynamics studies of fullerene-based HIV-1 PR inhibitors," Bioorganic and Medicinal Chemistry Letters, vol. 18, no. 23, pp. 6283-6289, 2008.

[28] M.-E. Suh, S.-Y. Park, and H.-J. Lee, "Comparison of QSAR methods (CoMFA, CoMSIA, HQSAR) of anticancer $1-\mathrm{N}$ substituted imidazoquinoline-4,9-dione derivatives," Bulletin of the Korean Chemical Society, vol. 23, no. 3, pp. 417-422, 2002.

[29] S. J. Bang and S. J. Cho, "Comparative molecular field analysis (CoMFA) and comparative molecular similarity index analysis (CoMSIA) study of mutagen X," Bulletin of the Korean Chemical Society, vol. 25, no. 10, pp. 1525-1530, 2004.

[30] L. Ghemtio, Y. Zhang, and H. Xhaard, Virtual Screening, InTech, 2012.

[31] G. Klebe, 3D QSAR in Drug Design, vol. 3, Springer, 2002.

[32] G. Klebe and U. Abraham, "Comparative Molecular Similarity Index Analysis (CoMSIA) to study hydrogen-bonding properties and to score combinatorial libraries," Journal of ComputerAided Molecular Design, vol. 13, no. 1, pp. 1-10, 1999.

[33] I. Mitra, A. Saha, and K. Roy, "Pharmacophore mapping of arylamino-substituted benzo[b]thiophenes as free radical scavengers," Journal of Molecular Modeling, vol. 16, no. 10, pp. 1585-1596, 2010.

[34] K. Boppana, P. K. Dubey, S. A. R. P. Jagarlapudi, S. Vadivelan, and G. Rambabu, "Knowledge based identification of MAO-B selective inhibitors using pharmacophore and structure based virtual screening models," European Journal of Medicinal Chemistry, vol. 44, no. 9, pp. 3584-3590, 2009.

[35] M. Chopra, R. Gupta, S. Gupta, and D. Saluja, "Molecular modeling study on chemically diverse series of cyclooxygenase-2 selective inhibitors: generation of predictive pharmacophore model using Catalyst," Journal of Molecular Modeling, vol. 14, no. 11, pp. 1087-1099, 2008.

[36] A. Gaulton, L. J. Bellis, A. P. Bento et al., "ChEMBL: a large-scale bioactivity database for drug discovery," Nucleic Acids Research, vol. 40, pp. D1100-D1107, 2012.

[37] K. C. Shih, C. W. Shiau, T. S. Chen et al., "Automated chemical hypothesis generation and database searching with Catalyst," Perspectives in Drug Discovery and Design, vol. 3, pp. 1-20, 1995.

[38] D. F. Hsu and I. Taksa, "Comparing rank and score combination methods for data fusion in information retrieval," Information Retrieval, vol. 8, no. 3, pp. 449-480, 2005.

[39] C. C. Vogt and G. W. Cotrell, "Fusion via a linear combination of scores," Information Retrieval, vol. 1, no. 3, pp. 151-172, 1999.

[40] L. Xu, A. Krzyzak, and C. Y. Suen, "Methods of combining multiple classifiers and their applications to handwriting recognition," IEEE Transactions on Systems, Man and Cybernetics, vol. 22, no. 3, pp. 418-435, 1992.

[41] J.-M. Yang, Y.-F. Chen, T.-W. Shen, B. S. Kristal, and D. F. Hsu, "Consensus scoring criteria for improving enrichment in virtual screening," Journal of Chemical Information and Modeling, vol. 45, no. 4, pp. 1134-1146, 2005.

[42] M. A. Kuriakose, W. T. Chen, Z. M. He et al., "Selection and validation of differentially expressed genes in head and neck cancer," Cellular and Molecular Life Sciences, vol. 61, no. 11, pp. 1372-1383, 2004.

[43] K.-L. Lin, C.-Y. Lin, C.-D. Huang et al., "Feature selection and combination criteria for improving accuracy in protein structure prediction," IEEE Transactions on Nanobioscience, vol. 6, no. 2, pp. 186-196, 2007.

[44] G. T. Lountos, J. E. Tropea, D. Zhang et al., "Crystal structure of checkpoint kinase 2 in complex with NSC 109555, a potent and selective inhibitor," Protein Science, vol. 18, no. 1, pp. 92-100, 2009. 

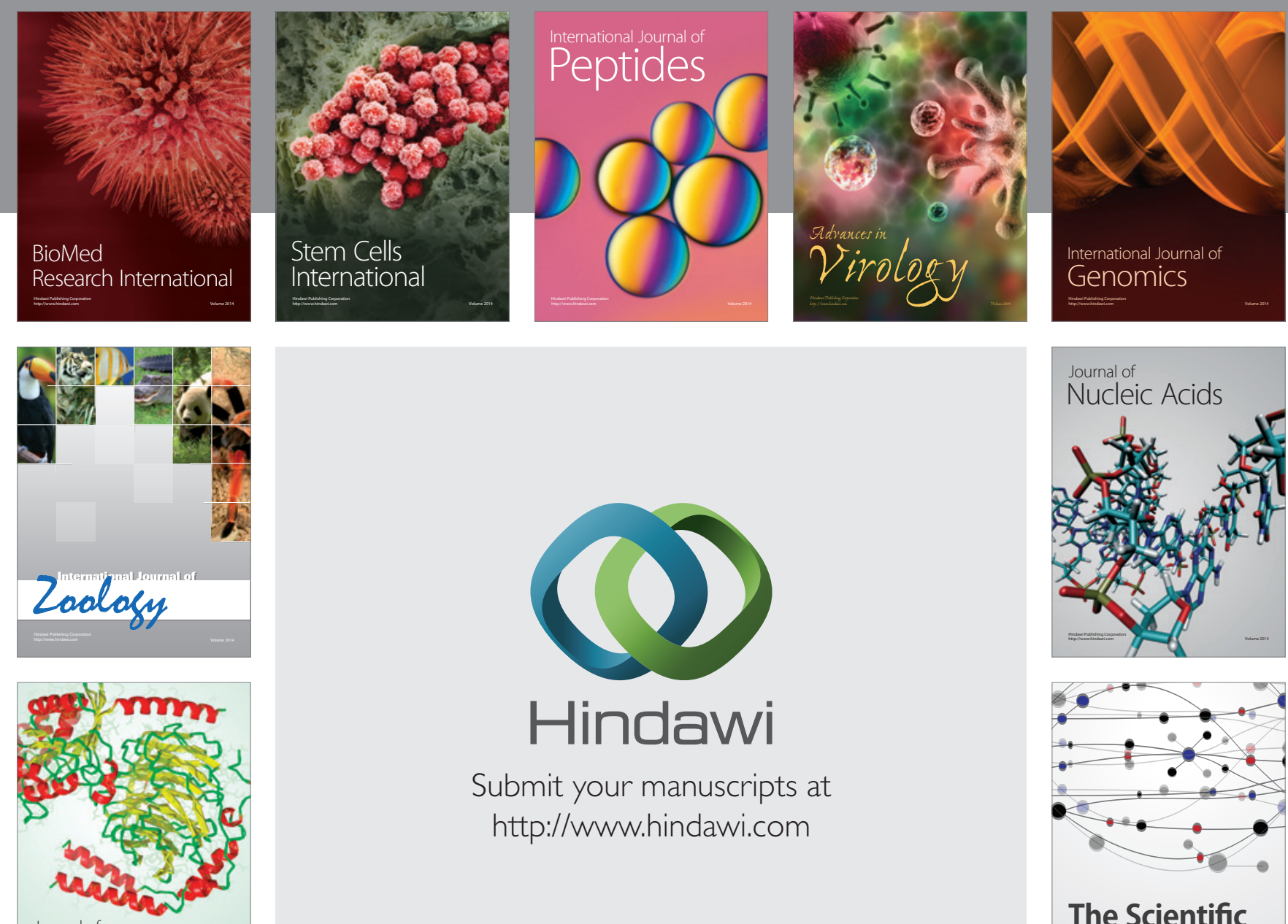

Submit your manuscripts at

http://www.hindawi.com

Journal of
Signal Transduction
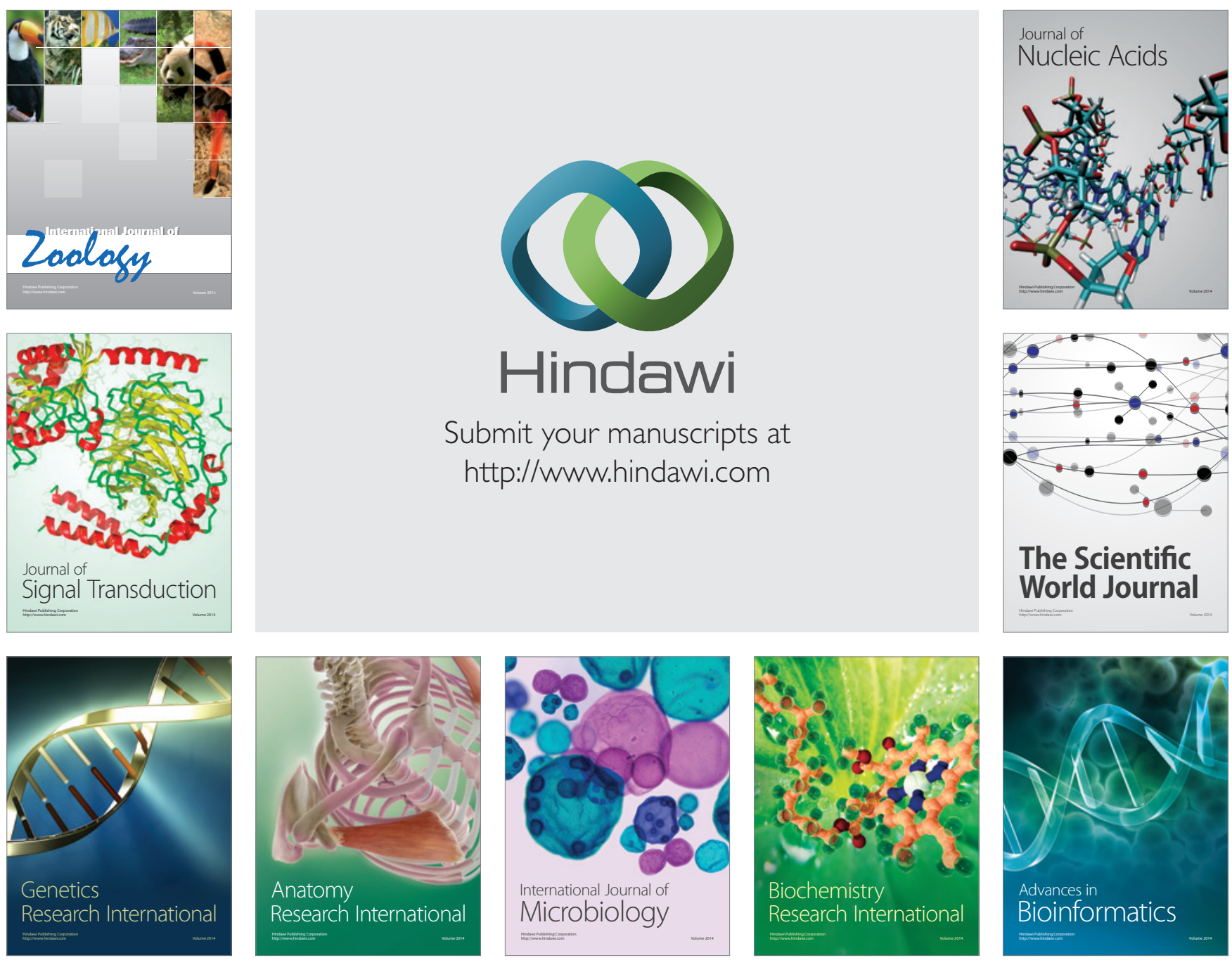

The Scientific World Journal
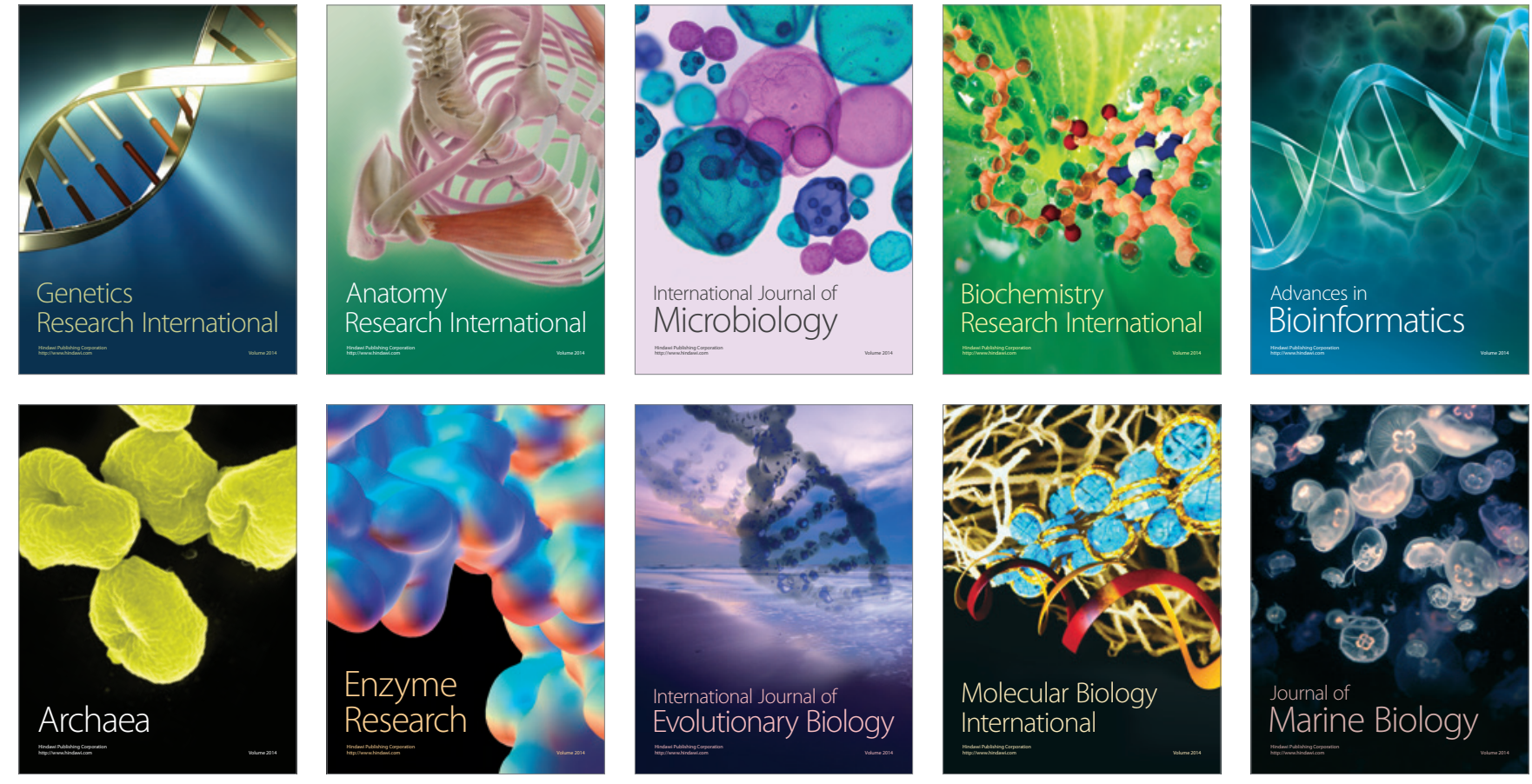